\title{
Tolerability of NGX-40 I 0, a capsaicin $8 \%$ patch, in conjunction with three topical anesthetic formulations for the treatment of neuropathic pain
}

\author{
This article was published in the following Dove Press journal: \\ Journal of Pain Research \\ 19 January 2012 \\ Number of times this article has been viewed
}

\author{
Lynn R Webster ${ }^{1}$ \\ John F Peppin ${ }^{2}$ \\ Frederick T Murphy ${ }^{3,4}$ \\ Jeffrey K Tobias ${ }^{5}$ \\ Geertrui F Vanhove ${ }^{5}$ \\ 'Lifetree Clinical Research and Pain \\ Clinic, Lifetree Medical Inc, Salt Lake \\ City, UT, USA; ${ }^{2}$ Clinical Research \\ Division, The Pain Treatment Center \\ of the Bluegrass, Lexington, $\mathrm{KY}$, \\ USA; ${ }^{3}$ Altoona Center for Clinical \\ Research, Duncansville, PA, USA; \\ ${ }^{4}$ University of Pennsylvania, School \\ of Medicine, Philadelphia, PA, USA; \\ ${ }^{5}$ NeurogesX Inc, San Mateo, CA, USA
}

Background: The objective of this study was to assess the safety, tolerability, and preliminary efficacy of NGX-4010, a capsaicin $8 \%$ patch, following pretreatment with three different topical anesthetics in patients with peripheral neuropathic pain.

Methods: This open-label, multicenter study enrolled 117 patients with post-herpetic neuralgia, HIV-associated distal sensory polyneuropathy, or painful diabetic neuropathy. Patients received pretreatment with one of three lidocaine $4 \%$-based topical anesthetics (L.M.X. $4^{\circledR}$ [Ferndale Laboratories Inc, Ferndale, MI], Topicaine ${ }^{\circledR}$ Gel [Estela Basso, Jupiter, FL], or Betacaine Enhanced Gel 4 [Tiberius Inc, Tampa, FL]) for 60 minutes followed by a single 60- or 90-minute NGX-4010 application, and were followed for 12 weeks. Tolerability and safety measures included "pain now" Numeric Pain Rating Scale (NPRS) scores, dermal assessments, medication use for treatment-related pain, adverse events (AEs), clinical laboratory parameters, physical examinations, and vital signs. The primary efficacy variable was the percentage change in mean NPRS scores for "average pain for the past 24 hours" from baseline to weeks 2 through 12 .

Results: Treatment with NGX-4010 following pretreatment with any of the three topical anesthetics was generally safe and well tolerated. Nearly all patients completed $\geq 90 \%$ of the planned NGX-4010 application duration. The most common treatment-related AEs, applicationsite burning and application-site pain, were transient, mostly mild or moderate, and could be adequately managed by local cooling or short-acting oral opioid analgesics. Although slightly more patients used medication for treatment-related discomfort following pretreatment with Topicaine compared with L.M.X.4 or Betacaine, there were no statistical differences between the topical anesthetics. Neuropathic pain reduction from baseline to weeks 2 through 12 was approximately $30 \%$ and was similar among the topical anesthetics; the proportion of responders ranged from $45 \%$ to $50 \%$.

Conclusion: Treatment with NGX-4010 following pretreatment with any of the three topical anesthetics was generally safe and well tolerated; no significant differences in the parameters measured were noted between the pretreatment groups.

Keywords: neuropathic pain, capsaicin patch, tolerability, topical anesthetics

\section{Background}

Lifetree Clinical Research, 3838 South

700 East, Suite 202, Salt Lake City,

UT 84106, USA

Tel + I 8012698200

Fax + 80| 26|334|

Email LRWebsterMD@gmail.com
Neuropathic pain is a common condition that affects up to $8 \%$ of the European population. ${ }^{1-3}$ Established treatments for neuropathic pain are limited as they provide only partial pain relief in an estimated $40 \%-60 \%$ of patients, and many are associated with a variety of unwanted systemic effects and intensive daily regimens. ${ }^{4-7}$ 
Capsaicin, the main active capsaicinoid ingredient of chilies (Capsicum spp.), is an agonist of the transient receptor potential vanilloid 1 (TRPV1) receptor, ${ }^{8}$ which is highly expressed on nociceptors. ${ }^{5,9,10}$ NGX-4010 is a localized dermal delivery system containing high-concentration capsaicin $(8 \% \mathrm{w} / \mathrm{w})$ that is designed to rapidly deliver therapeutic doses of capsaicin locally into the skin. This results in defunctionalization of TRPV1-expressing sensory nerve endings and reduced epidermal nerve fiber density. ${ }^{11-14}$ Prolonged relief of neuropathic pain for up to 12 weeks following a single NGX-4010 application has been observed in patients with post-herpetic neuralgia (PHN) or painful HIV-associated distal sensory polyneuropathy (HIV-DSP) in Phase II and III studies. ${ }^{15-20}$

Due to the irritancy of capsaicin, topical application is associated with pain, erythema, and other application-site reactions. ${ }^{15-20}$ Because of this, a topical anesthetic is applied to reduce application-site discomfort prior to administration of NGX-4010. In the above clinical studies, a 4\% lidocaine topical anesthetic cream (L.M.X.4 $4^{\circledR} /$ ELA-Max4; Ferndale Laboratories Inc, Ferndale, MI) was applied for 60 minutes and removed prior to NGX-4010 application. The current open-label study sought to determine whether similar tolerability could be achieved with other commonly available $4 \%$ lidocaine formulations and assessed the safety, tolerability, and efficacy of NGX-4010 following pretreatment with either L.M.X.4 or the alternative products (Topicaine ${ }^{\circledR} \mathrm{Gel}$ [ESBA Laboratories Inc, Jupiter, FL] or Betacaine Enhanced Gel 4 [Theraderm Inc, Tampa, FL]).

\section{Methods}

\section{Patients}

The study was approved by a central institutional review board (BioMed IRB, San Diego, CA) or a local institutional review board at participating sites and conducted in accordance with the ethical principles of the Declaration of Helsinki, Good Clinical Practice guidelines, and applicable regulatory requirements. Written informed consent was obtained from all participating patients before initiating study-related procedures. The study is registered at clinicaltrials.gov (identifier NCT00082316).

Patients were at least 18 years old with moderate to severe neuropathic pain (average Numeric Pain Rating Scale [NPRS] score of 3-8 inclusive) for at least 3 months secondary to painful diabetic neuropathy (PDN), PHN, or HIV-DSP. The NPRS is an 11-point scale (0-10), with 0 indicating no pain and 10 indicating the worst possible pain. ${ }^{21}$ Patients taking chronic pain medications (anticonvulsants, nonselective serotonin reuptake inhibitor [SSRI] antidepressants, or opioids) had to be on a stable dose for at least 21 days before study patch application and remain on a stable dose throughout the 12-week study.

Exclusion criteria included the following: use of any topically applied pain medication on the painful area within 21 days before study patch application; history of diabetic foot ulcerations and/or status post-amputation; any implanted medical device for the treatment of neuropathic pain; significant ongoing or recurrent pain of another etiology that interfered with judging neuropathic pain; evidence of another contributing or immunologic cause for the sensory neuropathy; and neuropathic pain areas located only on the face, above the scalp hairline, or near mucous membranes.

\section{Procedures}

Patients were randomized to receive pretreatment for 60 minutes with one of three lidocaine 4\%-based topical anesthetics: L.M.X.4, Topicaine Gel, or Betacaine Enhanced Gel 4 followed by a 60- or 90-minute treatment with NGX-4010 (QUTENZA ${ }^{\circledR}$; NeurogesX Inc, San Mateo, CA). Up to four NGX-4010 patches of $280 \mathrm{~cm}^{2}$ could be used (maximum treatment area of $1120 \mathrm{~cm}^{2}$ ). Patients were randomly assigned to receive 60 or 90 minutes of treatment with NGX-4010 and allocated to one of three topical anesthetic arms according to a 1:1:1:1:1:1 randomization scheme generated by ICON Clinical Research (Redwood City, CA). Oxycodone oral solution $(1 \mathrm{mg} / \mathrm{mL})$ could be administered at the onset of treatment-associated discomfort and as needed in the clinic on treatment days. After patch removal, local cooling (such as cold compresses) could also be used to relieve treatment-associated discomfort. In addition, patients could take hydrocodone bitartrate/ acetaminophen $(5 \mathrm{mg} / 500 \mathrm{mg})$ for up to 5 days after patch application for treatment-associated discomfort as needed. Topical pain medications were not permitted. Throughout the study, patients were allowed to take acetaminophen up to $2 \mathrm{~g}$ /day as needed for pain.

\section{Safety}

Safety was assessed by adverse events (AEs), which were coded using the Medical Dictionary for Regulatory Activities, version 7.0. Treatment-associated erythema, discomfort, and pain on the day of treatment were not captured as AEs but reported as dermal assessment scores or NPRS scores.

Dermal assessment scores ( 0 - to 7-point severity score $)^{22}$ were recorded on the day of treatment before and after application of topical anesthetic, and 5 and 120 minutes after patch removal and at each study visit. The distribution of maximum score between the pooled L.M.X.4 group and 
the other two pooled anesthetic groups was compared using the Cochran-Mantel-Haenszel test.

On the day of treatment, "pain now" NPRS scores were recorded immediately prior to anesthetic application; 30 and 55 minutes after anesthetic application; 25, 55, and 85 (if applicable) minutes after patch application; and 5, 25, 55, 85 , and 115 minutes after patch removal. The change in NPRS scores from the pre-anesthetic time point, change in vital signs (systolic blood pressure, diastolic blood pressure, heart rate, and respiratory rate) from the pre-patch time point, the proportion of patients with a $\geq 33 \%$ increase in NPRS score from baseline during the first 48 hours after NGX-4010 treatment, and the proportion of patients with $<90 \%$ of intended patch application duration were summarized. A CochranMantel-Haenszel test adjusted for treatment duration (60 or 90 minutes) was used to test for a difference in the proportion of patients with $\mathrm{a} \geq 33 \%$ increase in NPRS score from baseline during the first 48 hours between the pooled L.M.X.4 group and the other two pooled anesthetic groups.

Descriptive statistics were calculated for laboratory parameters and vital signs at screening, termination, and change from screening to termination.

A chi-squared test was performed to test for a difference in the proportion of patients using medication for treatmentrelated discomfort between the pooled L.M.X.4 group and the other two pooled anesthetic groups.

A total of 126 subjects were planned for this study. The sample size was determined based on a chi-squared continuity corrected test to detect a difference of $20 \%$ in the proportion of subjects completing at least $90 \%$ of intended duration between the L.M.X.4-treated group and each of the other topical anesthetic groups at the 0.05 significance level with $80 \%$ power.

\section{Efficacy}

Efficacy was evaluated using NPRS scores for "average pain for the past 24 hours" recorded daily at 9 PM in a paper diary throughout the study period. Patient Global Impression of Change (PGIC; patients reported how they felt after treatment as compared with before treatment on a scale of -3 , indicating "very much worse," to +3 , indicating "very much improved," with 0 being "no change") and the investigatorrated Clinical Global Impression of Change (CGIC) ${ }^{23}$ were evaluated at weeks 2, 6, and 12 .

The primary efficacy endpoint was the percentage change in "average pain for the past 24 hours" NPRS scores from baseline to weeks 2 through 12. To avoid the potential confounding effect of allowed opioid medications during days $0-5$, week 1 scores were not included. Other efficacy measures included: mean absolute changes in NPRS scores and the proportion of patients with a $\geq 30 \%$ or $\geq 50 \%$ reduction in NPRS score from baseline to weeks 2 through 12; and the percentage of patients considered improved (slightly, much, or very much) on the PGIC or CGIC at week 12.

All patients who received any study treatment and had at least 3 days of available NPRS scores during the baseline period were included in the efficacy analyses. An analysis of covariance model with baseline pain score as the covariate was used to test for differences in change from baseline to weeks 2 through 12 between the pooled L.M.X.4 group and each of the other two pooled anesthetic groups. A logistic regression model, with the baseline NPRS score as covariate, was performed to test for a difference in the proportion of patients reaching 30\% and 50\% decreases from baseline between the pooled L.M.X.4 group and each of the other two pooled anesthetic groups.

\section{Results}

\section{Patients}

A total of 117 patients were enrolled and received NGX4010 treatment: 39 were pretreated with L.M.X.4, 38 with Topicaine, and 40 with Betacaine (Figure 1). Fourteen patients $(12 \%)$ terminated the study early; the number of early-terminating patients was similar among the three groups. No patients withdrew due to an AE. Six patients terminated early because of unsatisfactory therapeutic response, two from each topical anesthetic group.

The average age of patients enrolled in the studies ranged from 58 to 63 years (Table 1). The majority of patients were white, male, and had PDN. The average duration of pain ranged from 3.8 to 5.3 years, and baseline average pain scores ranged from 5.4 to 5.9. Slightly more than half of the patients were receiving concomitant neuropathic pain treatment consisting of anticonvulsants, non-SSRI antidepressants, or opioids at baseline.

\section{Safety}

NGX-4010 was well tolerated regardless of the pretreatment used. The proportion of patients completing at least $90 \%$ of the planned NGX-4010 patch application duration was $100 \%$ for Betacaine, 97\% for L.M.X.4, and 97\% for Topicaine. One patient pretreated with L.M.X.4 had NGX4010 inadvertently removed after 55 minutes instead of the intended 90 minutes, and one patient pretreated with Topicaine had NGX-4010 removed after 30 minutes instead of the intended 60 minutes, due to intolerability.

The proportion of patients with at least one AE ranged from $50 \%$ to $59 \%$ (Table 2 ). AEs were primarily 


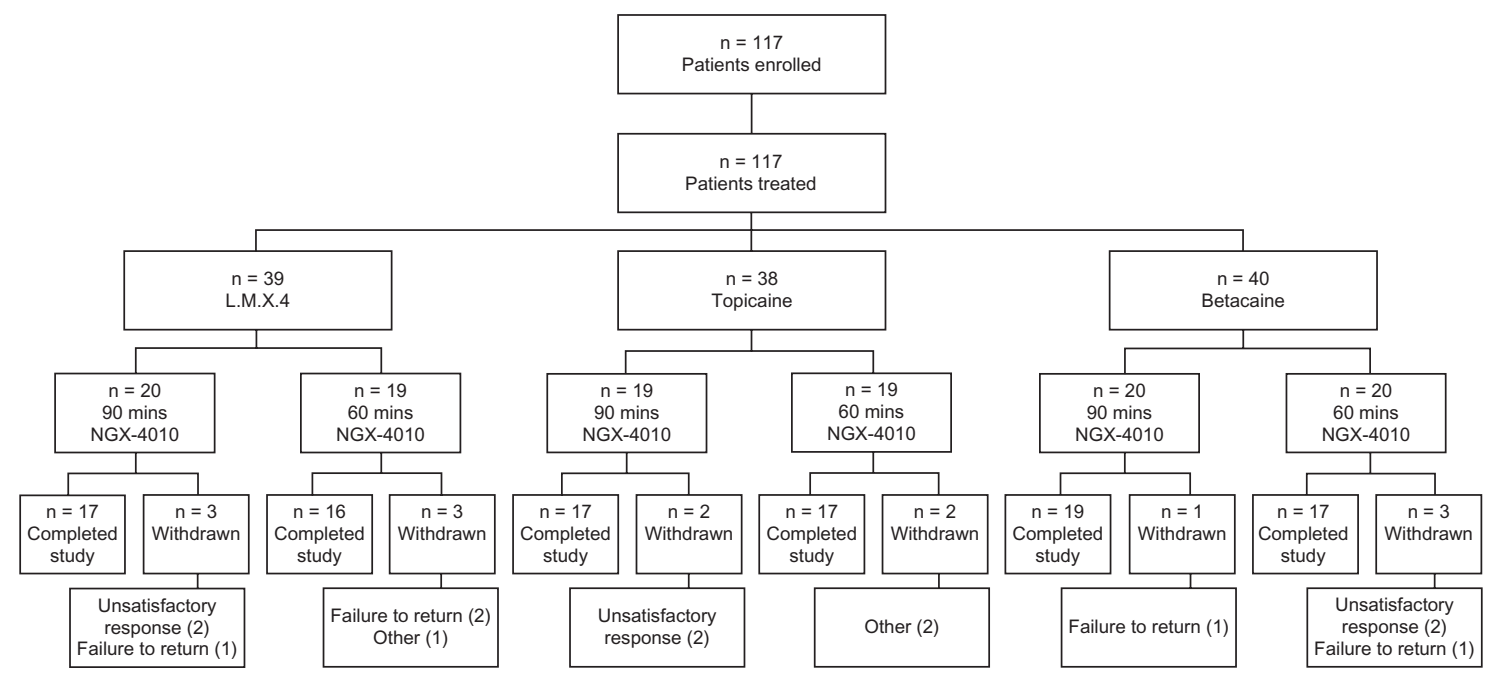

Figure I Overview of patient randomization and disposition.

capsaicin-related application-site events, which were reported by $30 \%-37 \%$ of patients. Common application-site events included application-site burning and applicationsite pain. Application-site events were transient, resolved within 1 or 2 days, and were mostly mild or moderate. The proportion of patients with severe application-site events was slightly greater in the Topicaine group ( 7 out of $38,18 \%$ ) compared with the L.M.X.4 (4 out of 39 , $10 \%$ ) or Betacaine (5 out of $40,13 \%$ ) groups and mostly consisted of application-site burning (data not shown). Serious AEs occurred in $6 \%$ of patients. No serious AE

Table I Demographics and baseline characteristics

\begin{tabular}{|c|c|c|c|}
\hline Patients & $\begin{array}{l}\text { L.M.X.4 } \\
(n=39)\end{array}$ & $\begin{array}{l}\text { Topicaine } \\
(n=38)\end{array}$ & $\begin{array}{l}\text { Betacaine } \\
(n=40)\end{array}$ \\
\hline Age (years), mean \pm SD & $63 \pm 13$ & $62 \pm 12$ & $58 \pm 11$ \\
\hline Male, \% & 56 & 61 & 58 \\
\hline \multicolumn{4}{|l|}{ Race, n (\%) } \\
\hline White & $28(72)$ & $28(74)$ & $34(85)$ \\
\hline Black or African American & $5(13)$ & $3(8)$ & $2(5)$ \\
\hline Asian & I (3) & 0 & 0 \\
\hline Other & $5(13)$ & $7(18)$ & $3(8)$ \\
\hline \multicolumn{4}{|c|}{ Neuropathic pain syndrome, n (\%) } \\
\hline PDN & $30(77)$ & $29(76)$ & $32(80)$ \\
\hline PHN & $9(23)$ & $8(2 I)$ & $8(20)$ \\
\hline HIV-DSP & 0 & $I(3)$ & 0 \\
\hline $\begin{array}{l}\text { Duration of pain (years), } \\
\text { mean } \pm S D\end{array}$ & $5.3 \pm 5.55$ & $4.5 \pm 4.90$ & $3.8 \pm 3.91$ \\
\hline $\begin{array}{l}\text { Baseline pain level, } \\
\text { mean } \pm \text { SD (range) }\end{array}$ & $\begin{array}{l}5.6 \pm 1.56 \\
(2.5-8.2)\end{array}$ & $\begin{array}{l}5.9 \pm 1.44 \\
(3.5-8.4)\end{array}$ & $\begin{array}{l}5.4 \pm 1.27 \\
(3.0-7.8)\end{array}$ \\
\hline $\begin{array}{l}\text { Baseline concomitant pain } \\
\text { medication use } \mathrm{e}^{\mathrm{a}}, \mathrm{n}(\%)\end{array}$ & $24(62)$ & $19(50)$ & $23(58)$ \\
\hline \multicolumn{4}{|c|}{$\begin{array}{l}\text { Note: a A patient was defined as being on concomitant pain medication if he/she was } \\
\text { on an anticonvulsant, non-SSRI antidepressant, or opioid that was used on day -I } \\
\text { and was taken for a total duration of at least } 7 \text { consecutive days. } \\
\text { Abbreviations: HIV-DSP, human immunodeficiency virus-associated distal sensory } \\
\text { polyneuropathy; PDN, painful diabetic neuropathy; PHN, post-herpetic neuralgia; }\end{array}$} \\
\hline
\end{tabular}

was considered related to treatment, and no patients died during the study.

On the day of treatment, mean "pain now" NPRS scores decreased following topical anesthetic application and increased following patch application but on average did not or only slightly exceeded pre-anesthetic treatment values (Table 3). No significant differences in the proportion of

Table 2 Treatment-emergent adverse events that occurred in more than one patient in any of the anesthetic groups

\begin{tabular}{|c|c|c|c|}
\hline $\begin{array}{l}\text { System organ class } \\
\text { preferred term }\end{array}$ & $\begin{array}{l}\text { L.M.X.4 } \\
(n=39)\end{array}$ & $\begin{array}{l}\text { Topicaine } \\
(\mathrm{n}=\mathbf{3 8})\end{array}$ & $\begin{array}{l}\text { Betacaine } \\
(n=40)\end{array}$ \\
\hline $\begin{array}{l}\text { Patients reporting one or more } \\
\text { treatment-emergent AEs, } n(\%)\end{array}$ & $23(59)$ & $19(50)$ & $23(58)$ \\
\hline Cardiac disorders, n (\%) & $2(5)$ & $2(5)$ & 0 \\
\hline Cardiac failure congestive & $2(5)$ & 0 & 0 \\
\hline Gastrointestinal disorders, n (\%) & $6(15)$ & $4(11)$ & $2(5)$ \\
\hline Nausea & $2(5)$ & $4(11)$ & 0 \\
\hline Toothache & $2(5)$ & 0 & I (3) \\
\hline $\begin{array}{l}\text { General disorders and } \\
\text { administration-site } \\
\text { conditions, } \mathrm{n}(\%)\end{array}$ & $13(33)$ & $14(37)$ & $12(30)$ \\
\hline Application-site burning & $7(18)$ & $8(2 I)$ & $3(8)$ \\
\hline Application-site dryness & $2(5)$ & 0 & $2(5)$ \\
\hline Application-site edema & 0 & $2(5)$ & 0 \\
\hline Application-site pain & $3(8)$ & $5(13)$ & $3(8)$ \\
\hline Application-site pruritus & I (3) & I (3) & $2(5)$ \\
\hline Application-site swelling & I (3) & $5(13)$ & $2(5)$ \\
\hline $\begin{array}{l}\text { Infections and } \\
\text { infestations, } \mathrm{n}(\%)\end{array}$ & $15(38)$ & $7(18)$ & $8(20)$ \\
\hline Nasopharyngitis & 0 & $4(I I)$ & I (3) \\
\hline Urinary tract infection & $2(5)$ & I (3) & I (3) \\
\hline $\begin{array}{l}\text { Musculoskeletal and } \\
\text { connective tissue } \\
\text { disorders, } \mathrm{n}(\%)\end{array}$ & $10(26)$ & $4(\mathrm{II})$ & $6(15)$ \\
\hline Muscle spasm & $2(5)$ & 0 & 0 \\
\hline Pain in extremity & I (3) & $2(5)$ & I (3) \\
\hline
\end{tabular}

Abbreviation: $A E$, adverse event. 
patients reporting a $\geq 33 \%$ pain increase from baseline during the first 48 hours were observed between the L.M.X.4 and Topicaine or Betacaine groups. The proportion of patients using oral analgesics, including opioids, for treatment-related discomfort on days 0 through 5 was slightly greater in the Topicaine group (66\%) compared with the L.M.X.4 (51\%) or Betacaine (50\%) groups, but the differences were not statistically significant.

Dermal irritation was generally mild and transient. The majority of patients had a maximum dermal assessment score of 2 or less, indicative of minor dermal irritation (Table 4). Maximum scores were typically recorded within 2 hours after patch removal; no significant differences were observed between the L.M.X.4 and Topicaine or Betacaine groups.

Regardless of the pretreatment used, there were no clinically relevant changes in vital signs or any laboratory parameters evaluated across treatment groups. Small, transient blood pressure changes were observed during and shortly after patch application and appeared to be associated with treatment-related changes in pain.

Table 3 Change in "pain now" NPRS score from before topical anesthetic application on the day of treatment

\begin{tabular}{|c|c|c|c|}
\hline & $\begin{array}{l}\text { L.M.X.4 } \\
(n=39)\end{array}$ & $\begin{array}{l}\text { Topicaine } \\
(\mathrm{n}=38)\end{array}$ & $\begin{array}{l}\text { Betacaine } \\
(n=40)\end{array}$ \\
\hline $\begin{array}{l}25 \text { min after patch } \\
\text { application, mean } \pm S D\end{array}$ & $-2.2 \pm 2.76$ & $-0.9 \pm 3.19$ & $-1.9 \pm 2.43$ \\
\hline $\begin{array}{l}55 \text { min after patch } \\
\text { application, mean } \pm S D\end{array}$ & $-0.9 \pm 3.72$ & $0.6 \pm 3.90$ & $-0.3 \pm 3.08$ \\
\hline $\begin{array}{l}\text { Within } 5 \text { min after patch } \\
\text { removal, mean } \pm \text { SD }\end{array}$ & $-0.8 \pm 3.29$ & $0.1 \pm 3.10$ & $-0.1 \pm 2.48$ \\
\hline $\begin{array}{l}25 \text { min after patch } \\
\text { removal, mean } \pm S D\end{array}$ & $-0.6 \pm 3.23$ & $-0.4 \pm 2.4 \mathrm{I}$ & $-1.0 \pm 2.56$ \\
\hline $\begin{array}{l}55 \text { min after patch } \\
\text { removal, mean } \pm S D\end{array}$ & $-0.5 \pm 3.55$ & $-0.7 \pm 2.53$ & $-1.1 \pm 2.93$ \\
\hline $\begin{array}{l}85 \text { min after patch } \\
\text { removal, mean } \pm S D\end{array}$ & $-0.3 \pm 3.48^{c}$ & $-0.8 \pm 2.68$ & $-1.4 \pm 2.96$ \\
\hline $\begin{array}{l}\text { I55 min after patch } \\
\text { removal, mean } \pm S D\end{array}$ & $-0.2 \pm 3.59$ & $-1.2 \pm 2.49$ & $-1.5 \pm 2.80$ \\
\hline $\begin{array}{l}\text { Patients reporting a } \\
\geq 33 \% \text { pain increase } \\
\text { from baseline during } \\
\text { the first } 48 \text { hours, } n(\%)\end{array}$ & $28(72)$ & $28(74)$ & $30(75)$ \\
\hline$P$ value ${ }^{\mathrm{a}}$ & - & 0.832 & 0.747 \\
\hline $\begin{array}{l}\text { Patients using medication } \\
\text { for treatment-related } \\
\text { discomfort during } \\
\text { days } 0-5, n(\%)\end{array}$ & $20(5 \mathrm{I})$ & $26(68)$ & $20(50)$ \\
\hline$P$ value $^{\mathrm{b}}$ & - & 0.195 & 0.922 \\
\hline
\end{tabular}

Notes: a $P$ value was computed from a Cochran-Mantel-Haenszel test, adjusted for treatment duration, comparing the proportions between the L.M.X.4 group and the other two topical anesthetic groups; ${ }^{\circ} P$ value was computed from a chi-squared test comparing the proportions between the L.M.X.4 group and the other two topical anesthetic groups; '38 patients only.

Abbreviation: SD, standard deviation.
Table 4 Maximum dermal assessment scores from removal of patch through termination

\begin{tabular}{|c|c|c|c|}
\hline Score $(0 \text { to } 7)^{a}$ & $\begin{array}{l}\text { L.M.X.4 } \\
(n=39)\end{array}$ & $\begin{array}{l}\text { Topicaine } \\
(n=38)\end{array}$ & $\begin{array}{l}\text { Betacaine } \\
(n=40)\end{array}$ \\
\hline $0, \mathrm{n}(\%)$ & $10(26)$ & $10(26)$ & $14(35)$ \\
\hline $\mathrm{I}, \mathrm{n}(\%)$ & $10(26)$ & $10(26)$ & $11(28)$ \\
\hline $2, \mathrm{n}(\%)$ & $15(38)$ & $17(45)$ & $13(33)$ \\
\hline $3, n(\%)$ & $2(5)$ & 0 & I (3) \\
\hline 4, n (\%) & I (3) & I (3) & I (3) \\
\hline $5, \mathrm{n}(\%)$ & I (3) & 0 & 0 \\
\hline $6, \mathrm{n}(\%)$ & 0 & 0 & 0 \\
\hline $7, \mathrm{n}(\%)$ & 0 & 0 & 0 \\
\hline$P$ value $^{b}$ & - & 0.916 & 0.284 \\
\hline
\end{tabular}

Notes: ${ }^{\mathrm{a}} 0=$ no evidence of irritation; $\mathrm{I}=$ minimal erythema, barely perceptible; 2 = definite erythema, readily visible; minimal edema or minimal papular response; 3 = erythema and papules; 4 = definite edema; 5 = erythema, edema, and papules; $6=$ vesicular eruption; $7=$ strong reaction spreading beyond test site. ${ }^{\mathrm{b}} \mathrm{P}$ value was computed from a Cochran-Mantel-Haenszel test comparing distribution of maximum score $(0, I, \geq 2)$ between the L.M.X.4 group and the other two topical anesthetics groups.

\section{Efficacy}

Patients reported a mean $27.2 \%-34.3 \%$ reduction in pain during weeks 2 through 12 (Table 5), and $45 \%-50 \%$ of patients were considered to have responded to treatment (ie, experienced a $\geq 30 \%$ mean decrease from baseline in pain). The proportion of patients who achieved a $\geq 50 \%$ decrease in pain scores from baseline to weeks 2 through 12 ranged from $28 \%$ to $37 \%$. There were no significant differences in pain reduction between the L.M.X.4 and Topicaine or Betacaine groups, and no trends were observed in NPRS scores between the 60- and 90-minute treatment groups (data not shown). Analysis of PGIC demonstrated that at week $12,58 \%-71 \%$ of patients considered themselves to have improved (slightly, much, or very much) and 35\%-42\% of patients reported being much or very much improved (Table 5). The results of the CGIC were similar.

\section{Discussion}

Treatment with NGX-4010 in conjunction with any of the three topical anesthetics tested was generally well tolerated with a good safety profile. Nearly all patients completed at least $90 \%$ of the planned NGX-4010 application duration, regardless of the topical anesthetic product applied. As expected, capsaicin-related local application-site reactions were the most common AEs and were transient, mostly mild to moderate, and self-limited. Application-site events were adequately managed by local cooling or, if needed, by short-acting oral opioid analgesics (the latter were used for treatment-related discomfort by approximately half of all patients). On the day of treatment, the majority of patients had minor dermal irritation irrespective of the topical anesthetic used. In general, NGX-4010 treatment for 60 minutes 
Table 5 Efficacy of NGX-40I0

\begin{tabular}{|c|c|c|c|}
\hline & L.M.X.4 & Topicaine & Betacaine \\
\hline \multicolumn{4}{|l|}{ NPRS scores } \\
\hline Baseline, LS mean \pm SE & $5.6 \pm 0.23$ & $5.9 \pm 0.23$ & $5.4 \pm 0.23$ \\
\hline Weeks 2-12, n & 39 & 38 & 40 \\
\hline Actual (LS mean $\pm \mathrm{SE})$ & $3.9 \pm 0.32$ & $3.8 \pm 0.33$ & $4.0 \pm 0.32$ \\
\hline $\begin{array}{l}\text { Change from baseline } \\
(\mathrm{LS} \text { mean } \pm \mathrm{SE})\end{array}$ & $-1.7 \pm 0.32$ & $-1.8 \pm 0.33$ & $-1.6 \pm 0.32$ \\
\hline $\begin{array}{l}\text { Percentage change from } \\
\text { baseline (LS mean } \pm \mathrm{SE} \text { ) }\end{array}$ & $-31.8 \pm 5.61$ & $-34.3 \pm 5.72$ & $-27.2 \pm 5.56$ \\
\hline$P$ value ${ }^{a}$ & - & 0.757 & 0.563 \\
\hline $\begin{array}{l}\text { Patients with } \geq 30 \% \\
\text { decrease from baseline } \\
\text { to weeks } 2-12, n(\%)\end{array}$ & $18(46)$ & $19(50)$ & $18(45)$ \\
\hline$P$ value $^{\mathrm{b}}$ & - & 0.588 & 0.864 \\
\hline $\begin{array}{l}\text { Patients with } \geq 50 \% \\
\text { decrease from baseline } \\
\text { to weeks } 2-12, n(\%)\end{array}$ & $13(33)$ & $14(37)$ & II (28) \\
\hline$P$ value $^{\mathrm{b}}$ & - & 0.610 & 0.608 \\
\hline \multicolumn{4}{|l|}{ PGIC } \\
\hline Week $12, \mathrm{n}$ & 36 & 37 & 38 \\
\hline $\begin{array}{l}\text { Much improved (very } \\
\text { much, much), n (\%) }\end{array}$ & $14(39)$ & $13(35)$ & $16(42)$ \\
\hline $\begin{array}{l}\text { Improved (very much, } \\
\text { much, slightly), } \mathrm{n}(\%)\end{array}$ & $21(58)$ & $24(65)$ & $27(7 \mathrm{I})$ \\
\hline
\end{tabular}

Notes: $P$ value was computed using ANCOVA to test for difference between the L.M.X.4 group and the other two topical anesthetic groups. ${ }^{\mathrm{D} P}$ value was computed using logistic regression to test for difference between the L.M.X.4 group and the other two topical anesthetic groups.

Abbreviations: ANCOVA, analysis of covariance; LS mean, least squares mean; NPRS, Numeric Pain Rating Scale; PGIC, Patient Global Impression of Change; SE, standard error.

was better tolerated than treatment for 90 minutes. In each anesthetic group, more patients treated with NGX-4010 for 90 minutes used medication for treatment-related discomfort than those treated for 60 minutes; patients treated for 90 minutes generally reported larger pain increases during the treatment procedure compared with those treated for 60 minutes; and maximum dermal assessment scores were generally lower in patients treated for 60 minutes compared with patients treated for 90 minutes (data not shown).

The incidence and severity of application-site events and the proportion of patients using oral analgesics for treatment-related discomfort were slightly greater following pretreatment with Topicaine than following pretreatment with L.M.X.4 or Betacaine. However, differences in medication use were not statistically significant and likely related to the relatively small sample size.

Since the systemic absorption of capsaicin after application of NGX-4010 is minimal, ${ }^{24}$ the lack of effect of NGX-4010 on any laboratory parameter evaluated was expected.

The analyses of NPRS scores and PGIC indicate that the selection of topical anesthetic had no influence over the pain relief obtained with NGX-4010. Indeed NGX-4010 resulted in prolonged pain relief for up to 12 weeks following a single application of NGX-4010 in all groups; other efficacy endpoints also showed similar relief of pain across the different pretreatment groups. Mean NPRS scores were reduced from baseline by approximately $30 \%$ in all groups, which is similar to the degree of pain relief reported previously in Phase III clinical trials of NGX-4010 in patients with PHN that utilized a 60-minute pretreatment with L.M.X.4. ${ }^{15,18}$

Limitations of the study included the lack of a control group. In addition, the sample size was insufficient to detect small differences between the topical lidocaine formulations in terms of tolerability and efficacy of NGX-4010. However, the study was sufficiently powered to detect a difference of $20 \%$ in the proportion of subjects completing at least $90 \%$ of intended duration between the L.M.X.4-treated group and each of the other topical anesthetic groups. As only a single patient was not able to tolerate the full duration of NGX-4010 application, and changes in mean NPRS scores were within the range reported in previous clinical trials in patients with PHN, ${ }^{15,18}$ the results from this study seem to indicate that when used as a pretreatment for NGX-4010, all of the topical formulations tested are similarly effective and do not impact on the efficacy of NGX-4010.

In conclusion, treatment with NGX-4010 in conjunction with any of the three topical anesthetics tested was generally safe and well tolerated. Regardless of the topical anesthetic used, there were no significant differences in tolerability. Relief of peripheral neuropathic pain from a single application of NGX-4010 was similar in the three topical anesthetic groups and comparable to the level of pain relief reported in previous Phase III clinical trials of NGX-4010 in patients with PHN. ${ }^{15,18}$ As few differences were seen between the three topical anesthetics tested and each topical anesthetic appeared to be a suitable pretreatment for NGX-4010, the results of this study suggest that clinicians can select a topical anesthetic formulation for pretreatment according to local clinical practice, product availability, and cost.

\section{Acknowledgments}

The authors would like to thank Stephen Chang, Biao Lu, and Chris Blair for their contribution to the statistical design and analysis as well as the following clinical investigators who enrolled patients in this study: Lisa Cohen, Joseph Dunn, Suzanne Gazda, Linda Glaser, James E Greenwald, Howard Kernstein, Michael Ledet, Michael Leong, Jeffrey Medoff, Martin Mollen, George Morgan, David Ross, Greg Silver, and Daniel Truong. Funding for this study was provided by NeurogesX Inc, San Mateo, CA, USA. Editorial assistance for manuscript styling and submission was provided by Adelphi 
Communications Ltd and was supported by Astellas Pharma Europe Ltd. (L.M.X.4 is a registered trade name of ferndale Laboratories Inc, Ferndale, MI, USA. ELA-Max is a cancelled registered trade name of ferndale Laboratories Inc, Ferndale, MI, USA. Topicaine is a registered trade name of Estela Basso, Jupiter, FL, USA. Betacaine is a cancelled registered trade name of Tiberius Inc, Tampa, FL, USA. QUTENZA is a registered trade name of NeurogesX Inc, San Mateo, CA, USA.)

\section{Disclosures}

In the previous 12 months, Lynn R Webster has provided consultancy for, been on an advisory board for, or received honoraria from AlphaBioCom, American Board of Pain Medicine, AstraZeneca, Boston Scientific, Cephalon Inc, Covidien Mallinckrodt, Nevro Corporation, and Theravance. John F Peppin is a consultant for NeurogesX Inc and Astellas Pharma Europe Ltd. Jeffrey K Tobias is consultant to and former employee of NeurogesX and owns NeurogesX stock. Geertrui F Vanhove was a NeurogesX employee and owns NeurogesX stock. Frederick T Murphy has no competing interests.

\section{References}

1. Bouhassira D, Lantéri-Minet M, Attal N, Laurent B, Touboul C. Prevalence of chronic pain with neuropathic characteristics in the general population. Pain. 2008;136:380-387.

2. Mallis Gagnon A, Furlan A, Lakha SF, Yegneswaran B. Systematic review of the prevalence of neuropathic pain. Eur J Pain. 2007;11 (Suppl 1):S202-S203 [Abstract No. 457].

3. Torrance N, Smith BH, Bennett MI, Lee AJ. The epidemiology of chronic pain of predominantly neuropathic origin. Results from a general population survey. J Pain. 2006; 7:281-289.

4. O'Connor AB, Dworkin RH. Treatment of neuropathic pain: an overview of recent guidelines. Am J Med. 2009;122(10 Suppl):S22-S32.

5. Noto C, Pappagallo M, Szallasi A. NGX-4010, a high-concentration capsaicin dermal patch for lasting relief of peripheral neuropathic pain. Curr Opin Investig Drugs. 2009;10:702-710.

6. Dworkin RH, O’Connor AB, Backonja M. Pharmacologic management of neuropathic pain: evidence-based recommendations. Pain. 2007; 132:237-251.

7. Stillman M. Clinical approach to patients with neuropathic pain. Cleve Clin J Med. 2006;73:726-739.

8. Caterina MJ, Schumacher MA, Tominaga M, et al. The capsaicin receptor: a heat-activated ion channel in the pain pathway. Nature. 1997;389:816-824

9. Szallasi A. Autoradiographic visualization and pharmacological characterization of vanilloid (capsaicin) receptors in several species, including man. Acta Physiol Scand. 1995;155(Suppl 629):1-68.

Journal of Pain Research

\section{Publish your work in this journal}

The Journal of Pain Research is an international, peer-reviewed, open access, online journal that welcomes laboratory and clinical findings in the fields of pain research and the prevention and management of pain. Original research, reviews, symposium reports, hypothesis formation and commentaries are all considered for publication.
10. Szallasi A, Blumberg PM. Vanilloid (capsaicin) receptors and mechanisms. Pharmacol Rev. 1999;51:159-211.

11. Kennedy WR, Vanhove GF, Lu SP, et al. A randomized, controlled, open-label study of the long-term effects of NGX-4010, a highconcentration capsaicin patch, on epidermal nerve fiber density and sensory function in healthy volunteers. J Pain. 2010;11:579-587.

12. Malmberg AB, Mizisin AP, Calcutt NA, et al. Reduced heat sensitivity and epidermal nerve fiber immunostaining following single applications of a high-concentration capsaicin patch. Pain. 2004;111:360-367.

13. Anand P, Bley K. Topical capsaicin for pain management: therapeutic potential and mechanisms of action of the new high-concentration capsaicin 8\% patch. Br J Anaesth. 2011;107:490-502.

14. McCormack PL. Capsaicin dermal patch: in non-diabetic peripheral neuropathic pain. Drugs. 2010;70:1831-1842.

15. Backonja M, Wallace MS, Blonsky ER, et al. NGX-4010, a highconcentration capsaicin patch, for the treatment of postherpetic neuralgia: a randomised, double-blind study. Lancet Neurol. 2008;7: 1106-1112.

16. Simpson DM, Estanislao L, Brown SJ, Sampson J. An open-label pilot study of high-concentration capsaicin patch in painful HIV neuropathy. J Pain Symptom Manage. 2008;35:299-306.

17. Simpson DM, Brown S, Tobias J. Controlled trial of high-concentration capsaicin patch for treatment of painful HIV neuropathy. Neurology. 2008;70:2305-2313.

18. Irving GA, Backonja M, Dunteman E, et al. A multicenter, randomized, double-blind, controlled study of NGX-4010, a high-concentration capsaicin patch, for the treatment of postherpetic neuralgia. Pain Med. 2011;12:99-109.

19. Backonja M, Malan TP, Vanhove GF, Tobias JK; for the C102/106 Study Group. NGX-4010, a high-concentration capsaicin patch, for the treatment of postherpetic neuralgia: a randomized, double-blind, controlled study with an open-label extension. Pain Med. 2010;11: 600-608.

20. Webster LR, Malan TP, Tuchman MM, Mollen MD, Tobias JK, Vanhove GF. A multicenter, randomized, double-blind, controlled dose finding study of NGX-4010, a high-concentration capsaicin patch, for the treatment of postherpetic neuralgia. J Pain. 2010;11:972-982.

21. Farrar JT, Young JP Jr, LaMoreaux L, Werth JL, Poole RM. Clinical importance of changes in chronic pain intensity measured on an 11-point numerical pain rating scale. Pain. 2001;94:149-158.

22. US Food and Drug Administration Center for Drug Evaluation and Research. Guidance for industry: skin irritation and sensitization testing of generic transdermal drug products. Washington, DC: US Department of Health and Human Services. Available from: http://www. fda.gov/ohrms/dockets/98fr/990236Gd.pdf\#search=\%22HillTop $\% 20$ Research\%2C\%20Inc.\%20dermal\%20irritation\%22. Accessed February 22, 2010.

23. Schneider LS, Clark CM, Doody R, et al. ADCS Prevention Instrument Project: ADCS-clinicians' global impression of change scales (ADCSCGIC), self-rated and study partner-rated versions. Alzheimer Dis Assoc Disord. 2006;20(4 Suppl 3):S124-S138.

24. Babbar S, Marier JF, Mouksassi MS, et al. Pharmacokinetic analysis of capsaicin after topical administration of a high-concentration capsaicin patch to patients with peripheral neuropathic pain. Ther Drug Monit. 2009;31:502-510.

The manuscript management system is completely online and includes a very quick and fair peer-review system, which is all easy to use. Visit http://www.dovepress.com/testimonials.php to read real quotes from published authors. 